\title{
Asthma Screening in Pediatric Sickle Cell Disease: A Clinic-Based Program Using Questionnaires and Spirometry
}

\author{
Sara C. Sadreameli, MD, MHS, Rachel O. Alade, MS, ${ }^{2, *}$ Peter J. Mogayzel, Jr., MD, PhD, \\ Sharon McGrath-Morrow, MD, MBA, and John J. Strouse, MD, $\mathrm{PhD}^{2, \dagger}$
}

A clinician diagnosis of asthma is associated with increased morbidity and mortality in people with sickle cell disease (SCD). We hypothesized that a screening program would help identify children with asthma needing referral to pulmonary clinic. We conducted a single-center project to screen patients with SCD for asthma using a previously validated questionnaire (Breathmobile) and for pulmonary function abnormalities with portable spirometry. Participants with a positive questionnaire and/or abnormal spirometry were referred to pediatric pulmonary clinic. We evaluated clinical associations with abnormal spirometry and questionnaire responses. Of the 157 participants, $58(37 \%)$ had a positive asthma screening questionnaire. Interpretable spirometry was available for 105 (83\% of those eligible) and of these, $35(34 \%)$ had abnormal results. The asthma questionnaire was $87.5 \%$ sensitive [95\% confidence interval (CI) $74.8-95.3$ ] and $85.3 \%$ specific $(95 \%$ CI 77.3-91.4) to detect a clinician diagnosis of asthma. Participants with positive questionnaires were older (mean age 12.2 vs. 9.9 years, $P=0.012$ ). Spirometry identified 16 additional participants who had normal asthma questionnaires. Seventy-four participants $(47 \%)$ were referred to pediatric pulmonary clinic and 25 (34\%) of these participants scheduled clinic appointments; however, only 13 (52\%) were evaluated in pulmonary clinic. Clinic-based asthma screening and spirometry frequently identified individuals with asthma and pulmonary function abnormalities. Only $22 \%$ of those referred were eventually seen in pulmonary clinic. The impact of improved screening and treatment on the pulmonary morbidity in SCD needs to be defined and is an area for future investigation. In addition, case management or multidisciplinary clinics may enhance future screening programs.

Keywords: sickle cell disease, Breathmobile, obstructive lung disease

\section{Introduction}

ICKLE CELl DISEASE (SCD) is the most common genetic $\checkmark$ disorder identified by newborn screening in the United States, and $\sim 2,600$ affected infants are born in North America each year. ${ }^{1}$ Sickle cell anemia, or hemoglobin SS, is usually the most severe form and accounts for $55 \%-65 \%$ of SCD diagnoses. ${ }^{2,3}$ People with SCD have acute and chronic complications related to sickled red blood cells that occlude blood vessels and cause hemolysis, anemia, inflammation, and end-organ damage. Pulmonary complications occur frequently and include chronic symptoms such as recurrent wheezing and chest tightness. These are often diagnosed by clinicians as asthma, sleep-disordered breathing, and obstructive and restrictive lung disease. ${ }^{4}$

A clinician diagnosis of asthma is associated with increased morbidity and affects $\sim 25 \%$ (range $20 \%-48 \%$ ) of pediatric patients with SCD, compared with $11 \%$ of the general population of African American youth in the United States. ${ }^{5-12}$ Asthma-like features such as wheezing, chest tightness, and cough occur in many pediatric patients with SCD. ${ }^{13}$ Airway hyperresponsiveness is also significantly more common in youth with SCD compared with the general population, regardless of asthma diagnosis. $^{14-18}$ The pathophysiology of these asthma-like features

\footnotetext{
${ }^{1}$ Eudowood Division of Pediatric Respiratory Sciences, and ${ }^{2}$ Division of Pediatric Hematology, Johns Hopkins University School of Medicine, Baltimore, Maryland.

*Current affiliation: Frank H. Netter School of Medicine, Quinnipiac University, North Haven, Connecticut.

${ }^{\dagger}$ Current affiliation: Divisions of Hematology and Pediatric Hematology/Oncology, Duke University School of Medicine, Durham, North Carolina.

This was presented in preliminary abstract form at the April 2014 Translational Science Meeting in Washington, District of Columbia.
} 
is not understood, and symptoms commonly attributed to asthma may overlap with symptoms that are due to underlying SCD; whether these features are best described as "asthma" is debatable. ${ }^{19-21}$ Regardless, a 2- to 3-fold increased risk of hospitalizations for acute chest syndrome and severe pain episodes and 2-fold higher mortality has been described for children with SCD with asthma, compared with children with SCD who have not been diagnosed with asthma. ${ }^{6,8}$

Abnormal pulmonary function also occurs in SCD and is not necessarily associated with an asthma diagnosis or symptoms. ${ }^{18,22,23}$ Lower airway obstruction affects between $13 \%$ and $35 \%$ of children and adolescents with SCD. ${ }^{24-27}$ Restrictive lung disease occurs in $9 \%-27 \%$ and becomes more prevalent with increasing age. ${ }^{24,26-28}$ Although a retrospective study reported an association between lower airway obstruction and more frequent episodes of acute chest syndrome and acute pain, ${ }^{7}$ a recent prospective study did not confirm this association. ${ }^{29}$ Presently, routine screening with pulmonary function tests is not recommended in SCD. ${ }^{30}$

Studies have suggested that children and adolescents without SCD with asthma who receive asthma care from a specialist receive higher quality care than those who do not receive specialty care. ${ }^{31,32}$ Care provided by a specialist has 3 main benefits: (1) it is more likely to be consistent with national asthma guidelines, (2) patients are more likely to be prescribed a preventative medication, and (3) patients are more likely to have written instructions for handling acute asthma exacerbations. ${ }^{33}$ Children and adolescents with SCD may have greater benefit from subspecialty pulmonary care as their symptoms may also be due to their underlying SCD and clinical presentations may be complex. Despite the most recent NHLBI evidence-based sickle cell guidelines' recommendation against routine pulmonary care or screening, ${ }^{30}$ some experts have recommended that children with asthma and SCD be seen twice yearly by an asthma specialist and have annual pulmonary function testing. ${ }^{5}$

To improve screening for asthma and increase appropriate referrals and visits to pulmonary clinic, we implemented routine screening in our pediatric hematology clinic and infusion center. We hypothesized that a screening program with facilitated referral would increase the proportion of patients identified with asthma and/or asthma-like symptoms and/or abnormal spirometry and evaluated by a pediatric pulmonologist.

\section{Methods and Materials}

Our study was originally reviewed by the Johns Hopkins IRB and classified as an exempt quality improvement project. We later obtained IRB approval to retrospectively review and report our results, including our screening program results and clinical characteristics.

We screened children and adolescents with SCD between 2 and 21 years old during scheduled appointments. These occurred in the pediatric hematology clinic and the pediatric infusion center at the Johns Hopkins Hospital from October 1, 2012 through June 30, 2013. All participants were screened with a paper version of the Breathmobile asthma screening questionnaire. ${ }^{34}$ Study staff distributed surveys during the clinic visit and used a predefined written scoring algorithm (sensitivity of $83 \%$ and specificity of $85 \%$ for a clinical diagnosis of asthma in children without SCD). The survey had been validated in a large, inner city, pediatric population of otherwise healthy youth. ${ }^{34}$ The Breathmobile questionnaire included 10 questions and was completed by a parent/guardian or patients $>17$ years old. The forms were immediately scored by study staff as either positive or negative and results communicated to the patient/ family. All participants 5 years and older, who were able to cooperate, performed prebronchodilator spirometry, using a portable spirometer (MicroLab by MD Spiro, Lewiston, ME). Spirometry was performed by a trained research assistant or a pulmonologist according to American Thoracic Society (ATS) quality and reproducibility standards. ${ }^{35}$ Spirometry was reported as percent predicted values according to standardized reference equations (NHANES III, Wang-Hankinson) ${ }^{36,37}$ and interpreted by a pediatric pulmonologist with overreading by a second pediatric pulmonologist. We defined lower airway obstruction as: FEV1 $<80 \%$ predicted with FVC $\geq 80 \%$ and FEV1/ FVC $<80 \%$, and suggestion of restriction (which can only be confirmed through other means, such as plethysmography) as: FEV $1<80 \%$ with FEV1/FVC $\geq 80 \%$. Spirometry results were batched for interpretation (approx. monthly) and mailed to patient's houses. Copies were given to the hematology provider who had seen the patient in clinic.

All participants received educational brochures about SCD and asthma. Those with a positive questionnaire and/or abnormal spirometry were referred to the pediatric pulmonary clinic at Johns Hopkins for further evaluation. Study staff offered assistance in scheduling a pulmonary appointment to all those who screened positive. Staff also sent reminder letters and magnets with the appointment date and pulmonary clinic phone number to participants who screened positive.

We performed chart review to collect data on: (1) SCDmodifying treatments (current use of hydroxyurea or chronic transfusion protocol), (2) type of SCD (from clinic notes and/or problem list), and (3) clinician diagnosis of asthma from the electronic medical record. A clinician diagnosis of asthma was defined as: (1) provider documentation of asthma or reactive airway disease in the clinic or infusion center note on the day of screening and (2) home use of at least 1 asthma medication (ie, inhaled beta adrenergic receptor agonist, inhaled corticosteroid, leukotriene antagonist, or combination inhaled corticosteroid/beta adrenergic receptor agonist). ${ }^{13}$ For occasional cases in which clarification was needed, preceding clinical notes were also evaluated (including emergency department and prior clinic notes). Participants who had clinical documentation of an asthma diagnosis but no current asthma medications prescribed and vice versa were classified as nonasthmatic.

We used Stata IC/13 (StataCorp, College Station, TX) for statistical analysis. We created visual displays to explore data. We evaluated the association between clinical characteristics and a positive asthma questionnaire or a clinician diagnosis of asthma by the chi-squared statistic and simple and multiple regression models. We used Student's $t$-test and simple and multiple linear regression models to evaluate spirometry results among groups. We compared the proportion of patients seen in pulmonary clinic before and after our screening program by Fisher's exact test.

\section{Results}

\section{Baseline data before intervention}

In the year before our screening project, 227 patients $\geq 2$ years of age with SCD were seen in the pediatric hematology 
Table 1. Patient Characteristics by Asthma Screening Questionnaire Results and Clinician-Diagnosed Asthma

\begin{tabular}{lcccccc}
\hline & $\begin{array}{c}(-) \text { Asthma } \\
\text { screening } \\
\text { questionnaire, } \\
\mathrm{N}=99\end{array}$ & $\begin{array}{c}\text { (+) Asthma } \\
\text { screening } \\
\text { questionnaire, } \\
\mathrm{N}=58\end{array}$ & $\mathrm{P}$ & $\begin{array}{c}(-) \\
\text { Asthma } \\
\text { diagnosis } \\
\mathrm{N}=109\end{array}$ & $\begin{array}{c}\text { (+) Asthma } \\
\text { diagnosis, } \\
\mathrm{N}=48\end{array}$ & $\mathrm{P}$ \\
\hline Male sex, $N(\%)$ & $41(41)$ & $30(52)$ & 0.21 & $43(39)$ & $28(58)$ & 0.03 \\
Type of SCD & & & & & & \\
$\quad$ HbSS, $N(\%)$ & $70(71)$ & $42(72)$ & 0.12 & $75(70)$ & $37(77)$ & 0.03 \\
$\quad$ HbSC, $N(\%)$ & $23(23)$ & $8(14)$ & 8 & $27(22)$ & $4(8)$ & \\
$\quad$ HbS $\beta^{+}$thal, $N(\%)$ & $6(6)$ & $8(14)$ & & $7(7)$ & $7(15)$ & \\
Age (mean \pm SD) & $9.9 \pm 5.8$ & $12.2 \pm 5.3$ & 0.008 & $10.5 \pm 6.1$ & $11.4 \pm 4.7$ & 0.35 \\
Asthma diagnosis, $N(\%)$ & $6(6)$ & $42(72)$ & $<0.0001$ & $\mathrm{~N} / \mathrm{A}$ & $\mathrm{N} / \mathrm{A}$ & $\mathrm{N} / \mathrm{A}$ \\
Hydroxyurea, $N(\%)$ & $26(26)$ & $21(36)$ & 0.189 & $29(27)$ & $18(38)$ & 0.17 \\
Chronic transfusions, $N(\%)$ & $11(11)$ & $16(28)$ & 0.008 & $11(10)$ & $16(33)$ & $<0.0001$ \\
Lower airway obstruction & $7(7)$ & $9(16)$ & 0.315 & $10(9)$ & $6(13)$ & 0.96 \\
FEV1\% predicted (mean $\pm \mathrm{SD})$ & $89.5 \pm 13.9$ & $87 \pm 14.3$ & 0.37 & $88.8 \pm 12.5$ & $87.7 \pm 16.3$ & 0.69 \\
\hline
\end{tabular}

${ }^{\mathrm{a}}$ Clinician diagnosis of asthma (physician diagnosis $+\geq 1$ asthma medication).

${ }^{\mathrm{b}}$ Interpretable spirometry $N=105$.

N/A, not applicable; SCD, sickle cell disease.

clinic, but only 4 of these patients $(2 \%)$ were also seen in pediatric pulmonary clinic. Spirometry was performed in 4 patients $(2 \%)$. If we assume a $20 \%$ prevalence of asthma in pediatric patients with SCD, we would expect 45 patients followed in our SCD center to have asthma.

\section{Participant characteristics}

We approached 159 clinic patients, and 157 (98\%) agreed to participate; demographic information is provided in Table 1. The 157 patients, who participated in screening, represented $73 \%$ of 214 eligible patients (ages 2-21) seen during the period of the quality improvement intervention. Patients who were not screened were most often missed because of a high volume of patients being seen in some clinic sessions. Occasionally patients were not screened due to the patient's acute illness (ie, pain or respiratory illness) and inability to cooperate with spirometry maneuvers. One hundred twelve $(71 \%)$ of participants had $\mathrm{HbSS}$ or a SCD of similar severity $\left(\mathrm{HbS} \beta^{0}\right.$ thalassemia or HbSD). Twenty-seven participants (17\%) were treated with chronic transfusions, and $47(30 \%)$ were prescribed hydroxyurea. Forty-eight (31\%) participants had a clinician diagnosis of asthma.

\section{Asthma screening questionnaires}

All 157 participants/caregivers completed the brief asthma screening questionnaire. Ninety-nine $(63 \%)$ had a negative asthma screening questionnaire, and $58(37 \%)$ had positive results (Table 1). The asthma screening questionnaire was $87.5 \%$ sensitive [95\% confidence interval (CI) 74.8-95.3] and $85.3 \%$ specific (95\% CI 77.3-91.4) to detect cliniciandiagnosed asthma using our standardized definition. The positive predictive value was $72.4 \%$ (95\% CI 59.1-83.3) and negative predictive value $93.9 \%$ (95\% CI 87.3-97.7).

\section{Clinical associations with positive asthma screening questionnaires}

Differences among baseline characteristics of participants with positive and negative asthma screening questionnaires are displayed in Table 1. Forty-two (88\%) participants with a clinician diagnosis of asthma had a positive asthma screening questionnaire, but only 2 participants with a clinician diagnosis of asthma had a negative screening questionnaire $(P<0.0001)$. In addition, 16 participants screened positive on the questionnaire, but did not meet the criteria for a clinician diagnosis of asthma. Participants with a positive asthma screening questionnaire were generally older than those with negative results (Table 1).

Sex, type of SCD, lower airway obstruction (FEV1/FVC ratio $<80 \%$ ), FEV1, and hydroxyurea use were not significantly different between participants with positive and negative asthma screening questionnaires (Table 1). Participants receiving chronic transfusions were more likely to have a positive asthma screening questionnaire [unadjusted logistic regression model OR $3,(P=0.01,95 \%$ CI $1.3-7.1)$; adjusted model (including type of SCD, age): OR 2.9 $(P=0.018,95 \%$ CI 1.2-7.1)]. Participants receiving chronic transfusions were also more likely to have a clinician diagnosis of asthma [unadjusted model OR $4.5(P=0.001$, 95\% CI 1.9-10.6); adjusted model OR $4.6(P=0.001,95 \%$ CI 1.9-11.5)].

\section{Spirometry results}

Participants who were 5 years or older performed spirometry (Fig. 1). Of 105 participants with interpretable spirometry, 35 (33\%) had abnormal results: 16 (15\%) had lower airway obstruction and $19(17 \%)$ had spirometric evidence suggestive of possible restrictive lung disease. The relationships among abnormal spirometry, screening questionnaire results, and asthma diagnosis (using our gold standard definition) are shown in a Venn diagram (Fig. 2). There was only fair overlap between abnormal spirometry and an abnormal screening questionnaire. Of the participants with interpretable spirometry results, $48(46 \%)$ had a positive asthma screening questionnaire. Spirometry identified $16(15 \%)$ additional participants with pulmonary function abnormalities who had a negative screening questionnaire. Of these 16, 2 had a clinical asthma diagnosis, and the 


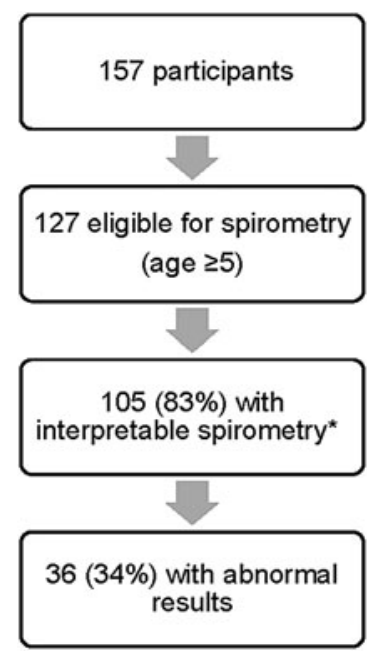

FIG. 1. Results of spirometry screening. $* 124$ participants performed spirometry. Two were missed due to malfunctioning spirometry equipment and 19 had uninterpretable spirometry due to poor technique.

remaining 14 had neither a documented asthma diagnosis nor a positive screening questionnaire. Nineteen (40\%) with positive asthma screening questionnaires also had abnormal spirometry results (either lower airway obstruction or the suggestion of restriction since restrictive ventilatory defects can only be diagnosed by lung volumes). There was no significant difference in mean FEV1 percent predicted between participants with a negative or positive asthma screening questionnaire (Table 1).

\section{Referral to and receipt of pediatric pulmonary care}

Seventy-four participants $(47 \%)$ were referred to pulmonary clinic on the basis of a positive asthma screening questionnaire, abnormal spirometry, or both. Only 25 of the referred patients $(34 \%)$ scheduled a pulmonary clinic ap- pointment, and $13(52 \%)$ of these patients were evaluated in pulmonary clinic. The other 12 patients with appointments missed or cancelled their appointments. Through our screening project, $6.1 \%$ of the pediatric population with SCD was seen in pulmonary clinic. This was a modest, but statistically significant increase after our screening program, compared with the proportion $(1.8 \%)$ before our project (risk difference $4.3 \%$ with 2 -sided Fisher's exact test $P=0.02$ ).

\section{Discussion}

We found that the previously validated Breathmobile asthma screening questionnaire was a simple and useful tool to improve asthma screening in the outpatient setting for pediatric patients with SCD. It was $88 \%$ sensitive and $85 \%$ specific to detect a clinician diagnosis of asthma. This is similar to its performance in the general pediatric population. ${ }^{34}$ Our results confirm those of a previously published study of 41 youth with SCD limited to $\mathrm{HbSS}$ or $\mathrm{HbS}-\beta^{0}$ thalassemia (sensitivity of $77 \%$ and specificity 100\%) in a larger and more diverse population of pediatric patients with SCD. ${ }^{38}$ Similar to these authors, we found that the questionnaire was easy to administer and correlated well with a clinician diagnosis of asthma. The asthma prevalence in our population of $31 \%$ is within the range that has been reported in SCD $(20 \%-48 \%)^{9,39-41}$

Children and adolescents with SCD are a particularly vulnerable population and identification of lung disease with referral to a pulmonologist for evaluation and treatment may improve clinical outcomes. Our pediatric hematology clinicand infusion center-based screening program modestly increased appropriate pulmonary referrals and visits for children and adolescents/young adults with SCD and could be implemented in a variety of practice settings.

Our study is limited by challenges in defining a gold standard for the diagnosis of asthma in children and adolescents/young adults with SCD and as previously noted, the concept that asthma may be an imperfect label for the airway disease in SCD. Furthermore, 16 participants had a

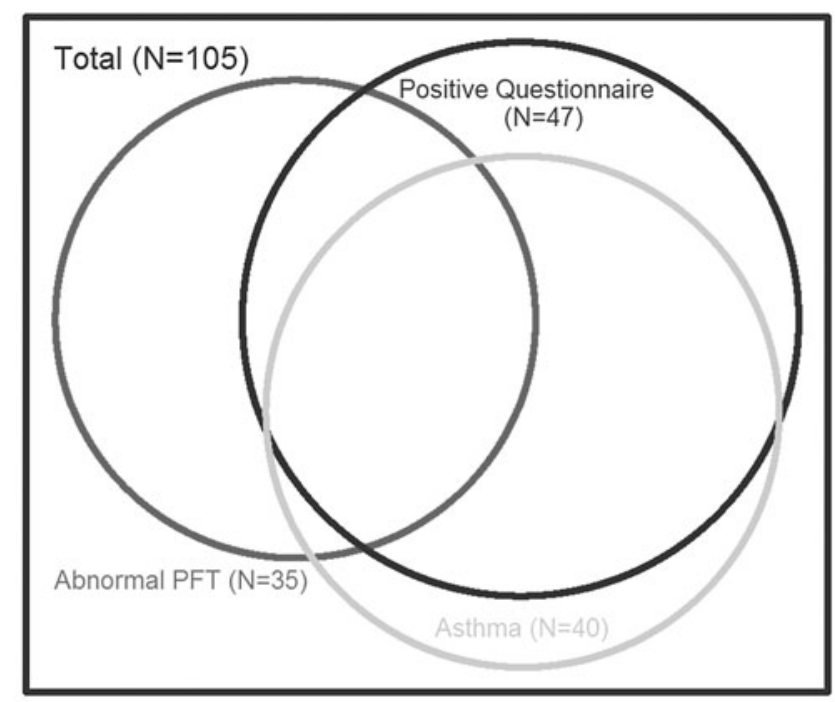

FIG. 2. Relationships between asthma diagnosis, screening questionnaire, and abnormal spirometry among participants who performed spirometry. PFT, pulmonary function test.

$\begin{array}{ll}\text { Abnormal spirometry } & \text { Positive Asthma Questionnaire } \\ \text { Clinician Asthma Diagnosis } & \text { Total Population }\end{array}$


positive asthma questionnaire despite not meeting our criteria for a clinician diagnosis of asthma. This suggests the presence of respiratory symptoms typical of asthma, despite not being labeled as asthma by a physician or treated with asthma medications. Anyone with a positive questionnaire would also likely benefit from evaluation, and possibly treatment, by a pulmonologist. A limitation of our screening program was reliance on a single cutoff of FEV1/FVC $<80 \%$ to define lower airway obstruction. It is preferred to use FEV1/FVC < lower limit of normal (LLN), which varies by age, sex, and race in children, to define lower airway obstruction. ${ }^{36}$ Because our project was intended to be a clinical screening program, we relied on a single portable spirometer that did not provide LLN. A single FEV1/FVC cutoff could have misclassified abnormal pulmonary function tests results as normal, and vice versa. If referred participants had come to pulmonary clinic, they would have had more thorough pulmonary function tests to determine whether they met the criteria for lower airway obstruction. We recommend utilizing the LLN for screening programs whenever possible.

Our screening program increased appropriate referrals and modestly increased visits to pulmonary clinic; however, only a minority of referred participants attended a pulmonary clinic visit. Further study is needed to determine the specific barriers to follow-up and the impact of interventions to increase adherence with clinic visits. Improved case management may help address some of these barriers. Another potential solution is the implementation of a multidisciplinary care model that integrates asthma and SCD care within the same visit. ${ }^{42}$ This approach has been shown to improve asthma care and even to correct lower airway obstruction in pediatric patients with SCD. ${ }^{43}$ Other factors that are associated with increased attendance in pulmonary clinic for referred patients with SCD are unknown. This is an important area for further investigation, as there may be other targets for intervention, particularly in locations where a multidisciplinary clinic is not feasible.

Spirometry requires additional resources (including trained and supervised staff, equipment, and disposable mouthpieces) and patient effort. However, we found that it was simple to implement in the pediatric hematology and infusion center, settings where it had not previously been done. Spirometry identified different children than the questionnaire in many cases (Fig. 2). This is consistent with other authors' descriptions of differences between clinical asthma diagnosis, asthma symptoms, and spirometry in children and adolescents/young adults with SCD. ${ }^{23,44}$ Routine screening with spirometry was not recommended in the most recent NHLBI SCD guidelines, which postdated our project ${ }^{30}$ as the clinical benefits of this screening are unclear. This must be balanced with the observation that decreased FEV1 is associated with an increased risk of pulmonary hypertension ${ }^{45}$ and death ${ }^{45,46}$ in SCD. Hydroxyurea treatment has recently been shown to slowly decline in pulmonary function in SCD. ${ }^{47}$ Perhaps spirometry could help identify patients who are experiencing declining pulmonary function. Because so few of our participants who were referred to pulmonary clinic kept the appointment, we are not able to report other results (symptoms, results of more comprehensive pulmonary function tests, etc.) in participants with abnormal spirometry alone. The impact of asthma treatment on morbidity and mortality in SCD is a major priority area for future research. Future research could also focus on caregiver and child factors that are associated with improved uptake of referrals to specialty care.

In summary, we describe a hematology clinic-based screening program in pediatric outpatients with SCD that identified patients who could benefit from specialty pulmonary care. We confirm results of a similar study ${ }^{38}$ and describe the performance of the Breathmobile questionnaire in a larger and more heterogeneous population of children and adolescents with SCD. We found the questionnaire to be an excellent screening tool that would be easy for others to implement in various clinical settings. Spirometry identified additional individuals ages 5 and older who could potentially benefit from pulmonary referral and evaluation who were not identified by the questionnaire or routine hematologist evaluation. Routine spirometry should be considered on a site-specific basis according to local resources and personnel. Other pulmonary conditions that occur in children with SCD include obstructive sleep apnea, exerciseinduced dyspnea, and pulmonary hypertension, which would warrant evaluation by a pediatric pulmonologist; future screening programs focused on pulmonary complications should also consider screening for symptoms of sleepdisordered breathing and exercise intolerance.

\section{Acknowledgments}

Project Funding Source: Thomas Wilson Sanitarium for Children of Baltimore City, 113029. Funding for Dr. Sadreameli during period of work: NIH T32 HL72748, NIH 1KL2TR001077-01.

\section{Author Disclosure Statement}

No competing financial interests exist.

\section{References}

1. Rees DC, Williams TN, Gladwin MT. Sickle-cell disease. Lancet 2010; 376:2018-2031.

2. Hertzberg VS, Hinton CF, Therrell BL, Shapira SK. Birth prevalence rates of newborn screening disorders in relation to screening practices in the United States. J Pediatr 2011; 159:555-560.

3. Lorey FW, Arnopp J, Cunningham GC. Distribution of hemoglobinopathy variants by ethnicity in a multiethnic state. Genet Epidemiol 1996; 13:501-512.

4. Gladwin MT, Vichinsky E. Pulmonary complications of sickle cell disease. N Engl J Med 2008; 359:2254-2265.

5. Anim SO, Strunk RC, DeBaun MR. Asthma morbidity and treatment in children with sickle cell disease. Expert Rev Respir Med 2011; 5:635-645.

6. Boyd J. Asthma is associated with acute chest syndrome and pain in children with sickle cell anemia. Blood 2006; 108:2923-2927.

7. Boyd J, DeBaun M, Morgan W, Mao J, Strunk R. Lower airway obstruction is associated with increased morbidity in children with sickle cell disease. Pediatr Pulmonol 2009; 44:290-296.

8. Boyd J, Macklin E, Strunk R, DeBaun M. Asthma is associated with increased mortality in individuals with sickle cell anemia. Haematologica 2007; 92:1115-1118.

9. Caboot JB, Allen JL. Pulmonary complications of sickle cell disease in children. Curr Opin Pediatr 2008; 20:279-287.

10. Knight-Madden JM, Forrester TS, Lewis NA, Greenough A. Asthma in children with sickle cell disease and its as- 
sociation with acute chest syndrome. Thorax 2005; 60:206210.

11. Nordness ME, Lynn J, Zacharisen MC. Asthma is a risk factor for acute chest syndrome and cerebral vascular accidents in children with sickle cell disease. Clin Mol Allergy $2005 ; 3: 2$.

12. Platt OS, Brambilla DJ, Rosse WF, Milner PF, Castro O, Steinberg MH, Klug PP. Mortality in sickle cell diseaselife expectancy and risk factors for early death. N Engl J Med 1994; 330:1639-1644.

13. Strunk RC, Cohen RT, Cooper BP, Rodeghier M, Kirkham FJ, Warner JO, Stocks J, Kirkby J, Roberts I, Rosen CL, Craven DI, DeBaun MR. Wheezing symptoms and parental asthma are associated with a physician diagnosis of asthma in children with sickle cell anemia. J Pediatr 2014; 164 : 821-826.e821.

14. Field JJ, Stocks J, Kirkham FJ, Rosen CL, Dietzen DJ, Semon T, Kirkby J, Bates P, Seicean S, DeBaun MR, Redline S, Strunk RC. Airway hyperresponsiveness in children with sickle cell anemia. Chest 2011; 139:563-568.

15. Ozbek OY, Malbora B, Sen N, Yazici AC, Ozyurek E, Ozbek N. Airway hyperreactivity detected by methacholine challenge in children with sickle cell disease. Pediatr Pulmonol 2007; 42:1187-1192.

16. Strunk RC, Brown MS, Boyd JH, Bates P, Field JJ, DeBaun MR. Methacholine challenge in children with sickle cell disease: a case series. Pediatr Pulmonol 2008; 43: 924-929.

17. Leong MA, Dampier C, Varlotta L, Allen JL. Airway hyperreactivity in children with sickle cell disease. J Pediatr 1997; 131:278-283.

18. Sylvester KP, Patey RA, Rafferty GF, Rees D, Thein SL, Greenough A. Airway hyperresponsiveness and acute chest syndrome in children with sickle cell anemia. Pediatr Pulmonol 2007; 42:272-276.

19. DeBaun MR, Strunk RC. The intersection between asthma and acute chest syndrome in children with sickle-cell anaemia. Lancet 2016; 387:2545-2553.

20. Cohen RT, Klings ES, Strunk RC. Sickle cell disease: wheeze or asthma? Asthma Res Pract 2015; 1:14.

21. Koumbourlis AC. Acute chest syndrome, asthma, and lung function in sickle cell disease. Which is the chicken, and which is the egg? Ann Am Thorac Soc 2016; 13:12121214.

22. Koumbourlis AC, Zar HJ, Hurlet-Jensen A, Goldberg MR. Prevalence and reversibility of lower airway obstruction in children with sickle cell disease. J Pediatr 2001; 138:188192.

23. Shilo NR, Alawadi A, Allard-Coutu A, Robitaille N, Pastore Y, Berube D, Jacob SV, Abish S, Dauletbaev N, Lands LC. Airway hyperreactivity is frequent in non-asthmatic children with sickle cell disease. Pediatr Pulmonol 2015; 51:950-957.

24. Lunt A, McGhee E, Sylvester K, Rafferty G, Dick M, Rees D, Height S, Thein SL, Greenough A. Longitudinal assessment of lung function in children with sickle cell disease. Pediatr Pulmonol 2016; 51:717-723.

25. Koumbourlis AC, Zar HJ, Hurlet-Jensen A, Goldberg MR. Prevalence and reversibility of lower airway obstruction in children with sickle cell disease. J Pediatr 2001; 138:188192.

26. Arteta M, Campbell A, Nouraie M, Rana S, Onyekwere OC, Ensing G, Sable C, Dham N, Darbari D, LuchtmanJones L, Kato GJ, Gladwin MT, Castro OL, Minniti CP, Gordeuk VR. Abnormal pulmonary function and associated risk factors in children and adolescents with sickle cell anemia. Am J Pediatr Hematol Oncol 2014; 36:185-189.

27. Intzes S, Kalpatthi RV, Short R, Imran H. Pulmonary function abnormalities and asthma are prevalent in children with sickle cell disease and are associated with acute chest syndrome. Pediatr Hematol Oncol 2013; 30:726-732.

28. Koumbourlis AC, Lee DJ, Lee A. Longitudinal changes in lung function and somatic growth in children with sickle cell disease. Pediatr Pulmonol 2007; 42:483-488.

29. Cohen RT, Strunk RC, Rodeghier M, Rosen CL, Kirkham FJ, Kirkby J, DeBaun MR. Pattern of lung function is not associated with prior or future morbidity in children with sickle cell anemia. Ann Am Thorac Soc 2016; 13:13141323.

30. Yawn BP, Buchanan GR, Afenyi-Annan AN, Ballas SK, Hassell KL, James AH, Jordan L, Lanzkron SM, Lottenberg R, Savage WJ, Tanabe PJ, Ware RE, Murad MH, Goldsmith JC, Ortiz E, Fulwood R, Horton A, John-Sowah J. Management of sickle cell disease: summary of the 2014 evidence-based report by expert panel members. JAMA 2014; 312:1033-1048.

31. Bartter T, Pratter MR. Asthma: better outcome at lower cost? The role of the expert in the care system. Chest 1996; 110:1589-1596.

32. Najada A, Abu-Hasan M, Weinberger M. Outcome of asthma in children and adolescents at a specialty-based care program. Ann Allergy Asthma Immunol 2001; 87:335-343.

33. Diette GB, Skinner EA, Nguyen TT, Markson L, Clark BD, $\mathrm{Wu} \mathrm{AW}$. Comparison of quality of care by specialist and generalist physicians as usual source of asthma care for children. Pediatrics 2001; 108:432-437.

34. Jones CA, Morphew T, Clement LT, Kimia T, Dyer M, Li M, Hanley-Lopez J. A school-based case identification process for identifying inner city children with asthma: the Breathmobile program. Chest 2004; 125:924-934.

35. Miller MR, Hankinson J, Brusasco V, Burgos F, et al. Standardisation of spirometry. Eur Respir J 2005; 26:319338.

36. Wang X, Dockery DW, Wypij D, Fay ME, Ferris BG, Jr. Pulmonary function between 6 and 18 years of age. Pediatr Pulmonol 1993; 15:75-88.

37. Hankinson JL, Odencrantz JR, Fedan KB. Spirometric reference values from a sample of the general U.S. population. Am J Respir Crit Care Med 1999; 159:179_ 187.

38. Yadav A, Corrales-Medina FF, Stark JM, Hashmi SS, Carroll MP, Smith KG, Meulmester KM, Brown DL, Jon C, Mosquera RA. Application of an asthma screening questionnaire in children with sickle cell disease. Pediatr Allergy Immunol Pulmonol 2015; 28:177-182.

39. Anim SO, Strunk RC, DeBaun MR. Asthma morbidity and treatment in children with sickle cell disease. Expert Rev Respir Med 2011; 5:635-645.

40. Boyd JH, Macklin EA, Strunk RC, DeBaun MR. Asthma is associated with increased mortality in individuals with sickle cell anemia. Haematologica 2007; 92:1115-1118.

41. Miller AC, Gladwin MT. Pulmonary complications of sickle cell disease. Am J Respir Crit Care Med 2012; 185 : 1154-1165.

42. Graham LM. Sickle cell disease: pulmonary management options. Pediatr Pulmonol Suppl 2004; 26:191-193.

43. McClain BL, Ivy ZK, Bryant V, Rodeghier M, DeBaun MR. Improved guideline adherence with integrated sickle cell disease and asthma care. Am J Prev Med 2016; 51 (1 Suppl 1):S62-S68. 
44. Boyd JH, DeBaun MR, Morgan WJ, Mao J, Strunk RC. Lower airway obstruction is associated with increased morbidity in children with sickle cell disease. Pediatr Pulmonol 2009; 44:290-296.

45. Chaturvedi S, Ghafuri DL, Kassim A, Rodeghier M, DeBaun MR. Elevated tricuspid regurgitant jet velocity, reduced forced expiratory volume in 1 second, and mortality in adults with sickle cell disease. Am J Hematol 2017; 92: 125-130.

46. Kassim AA, Payne AB, Rodeghier M, Macklin EA, Strunk $\mathrm{RC}$, DeBaun MR. Low forced expiratory volume is associated with earlier death in sickle cell anemia. Blood 2015; 126:1544-1550.

47. McLaren A, Klingel M, Behera S, Odame I, Kirby-Allen M, Grasemann H. Effect of hydroxyurea therapy on pul- monary function in children with sickle cell anemia. Am J Respir Crit Care Med 2017; 195:689-691.

Address correspondence to: Sara C. Sadreameli, MD, MHS Eudowood Division of Pediatric Respiratory Sciences Johns Hopkins University School of Medicine 200 N. Wolfe Street Baltimore, MD 21287

E-mail: ssadrea1@jhmi.edu

Received for publication April 20, 2017; accepted after revision October 23, 2017. 